\title{
Interdependence of Stock Markets Before and After the Global Financial Crisis of 2007
}

\author{
Boulis M. Ibrahim ${ }^{\text {a }}$ \\ Janusz Brzeszczynski ${ }^{\mathrm{b}}$ \\ Heriot-Watt University, Edinburgh
}

This version:

$30^{\text {th }}$ November, 2012

\footnotetext{
a Department of Accountancy Economics and Finance, Heriot-Watt University, Edinburgh, EH14 4AS, UK, Tel. +44 131451 3560, Fax + 44131451 3296, E-mail: b.m.ibrahim@hw.ac.uk

${ }^{\mathrm{b}}$ Department of Accountancy Economics and Finance, Heriot-Watt University,Edinburgh, EH14 4AS, UK, Tel. +44 131451 3294, Fax + 44131451 3296, j.brzeszczynski@hw.ac.uk
} 


\title{
Interdependence of Stock Markets Before and After the Global Financial Crisis of 2007
}

\author{
Boulis M. Ibrahim \\ Janusz Brzeszczynski \\ Heriot-Watt University, Edinburgh
}

\begin{abstract}
:
In this paper we analyse the evolution of interdependence and influence of major international stock markets (New York, London and Tokyo) before and after the Global Financial Crisis (GFC) of 2007. Using the framework of the Foreign Information Transmission (FIT) model of Ibrahim and Brzeszczynski (2009) we investigate first the direction and strength of simple meteor shower effects across those three markets and then focus our attention on other factors which may impact on the relations between the largest stock trading centres, namely: differentials in trading volume, differentials in stock price volatility and interest rate differentials. The results are robust to different models' specifications and they clearly indicate that the role of the US market as the influencer of the stock price movements in other markets has weakened after the GFC in 2007 while the role of the other two trading centres in the UK and Japan has strengthened. Our findings are consistent with the explanation related to the shift in balance of economic powers between countries.
\end{abstract}

Keywords: stock markets interdependence, meteor shower effects, Global Financial Crisis (GFC), Foreign Information Transmission (FIT) model

JEL classification: G15, G01, F65, F36, C32, C51 


\section{Introduction}

The Global Financial Crisis (GFC) of 2007 was a major event and an important milestone in the history of financial markets. Melvin and Taylor (2009) in their excellent review of incidents leading to the crisis and its further development after 2007 state that the GFC was in many respects unparalleled and had much stronger consequences than all earlier financial turmoil, which had much more muted global impact.

Melvin and Taylor (2009) chronicle main events of the GFC and notice that already in the early summer of 2007 it was apparent to many market participants that fixed income markets were under considerable stress after which equity markets experienced remarkable volatility in July 2007 . This was followed by the crisis in the foreign exchange markets in August 2007 when carry trade positions in major currencies started to unwind. Subsequently, the contagion has spread across different asset classes resulting in significant price movements and their volatility. The GFC moved later to Europe as many south European countries experienced macroeconomic problems and faced serious debt crisis.

In this paper we investigate the effects that the GFC has had on the evolution of interdependence of the three largest stock markets in New York, London and Tokyo before and after 2007. Previous evidence in the existing literature about the impact of financial turmoil on the return and volatility spillovers across financial markets is somewhat mixed. King and Wadhwani (1990) analysed correlations between US, UK and Japanese stock markets before and after the US stock market crash in 1987 and found a substantial increase of their interdependence following the 
event. Bertero and Mayer (1990) examined twenty three developed and emerging markets and presented evidence, based on monthly and daily frequency data, that their correlations with the US stock market have increased after the 1987 crash. Similar conclusions were reached in the study of Lee and Kim (1993) who applied weekly data. Hamao, Masulis and Ng (1991) examined markets in New York, London and Tokyo and found, using the framework of the GARCH-in-mean models, that volatility spillovers emanating from Japan have been gathering strength over time, especially after the 1987 crash in the US market. Forbes and Rigobon (2002) pointed out, however, that simple correlation coefficients applied in some of the earlier studies are a flawed measure, due to the failure to account for heteroscedasticity and the assumption about constant variance in relevant models, which results in overestimation of correlations across markets leading to incorrect conclusions about the nature and strength of markets interdependence. Their findings, based on the improved method which adjusts for the biases related to heteroscedasticity, showed no evidence of contagion during all the investigated crises in Mexico in 1994-1995, Asian crisis in 1997 and the US stock market crash in 1987. Forbes and Rigobon (2002) argue that the markets have been following a long-term trend of increasing market interdependence which continued from the periods before the financial turmoil and those episodes had little impact on the changes in their co-movements. Candelon, Hecq and Vershoor (2005) applied a different measure of interdependence based on business cycles and provided similar conclusions as Forbes and Rigobon (2002) that co-movement of markets existed in all periods in similar strength and there is no evidence of particular increase of its intensity during or after the financial crises. However, Bekaert, Harvey and $\mathrm{Ng}$ 
(2005), Corsetti, Pericoli and Sbracia (2005) and Nam, Yuhn and Kim (2008) reported results indicating evidence in favour of existence of contagion in case of the Asian crisis in 1997. In particular, Nam, Yuhn and Kim (2008) observed a tendency that the influence of the US market on the stock prices in major Asian markets in Hong Kong, Singapore, South Korea, Malaysia and Taiwan increased after the crisis but it decreased substantially in case of the impact on market volatility. On the other hand, Yilmaz (2010) reported results about increased return spillovers to East Asian equity markets but also evidenced bursts of volatility spillovers during major financial turmoil, including the East Asian crisis.

Our analysis in this paper is focused on the effects that the GFC has had on the stock markets using different methodology than those applied so far in the existing literature. We investigate changes in interdependence of stock market daily returns using the framework of the 'meteor shower' models, documented first in volatility by Engle et al. (1990) and in returns by Hamao et al. (1990) amongst others ${ }^{1}$, but we take advantage of a new methodological development in this field, namely the Foreign Information Transmission (FIT) model of Ibrahim and Brzeszczynski (2009). This approach allows one to analyze not only simple correlation relations between markets but also time-variation of their influence on each other in the chronological sequences in which they trade and within which they transmit information to each other. Ibrahim and Brzeszczynski (2009 and 2012) present evidence that the intensity of meteor showers in returns between pairs of

\footnotetext{
${ }^{1}$ Other relevant papers about signal transmission effects include: Ito, Engle and Lin (1992), Lin, Engle and Ito (1994), Longin and Solnik (2001), Bekaert, Harvey and $\mathrm{Ng}$ (2005), Masih and Masih (2001), Climent and Meneu (2003), Eun and Shim (1989), Bekaert and Harvey (1997 and 2000), Pagan and Schwert (1990), King and Wadhwani (1990), Bollerslev, Chou and Kroner (1992), Adjaoute, Bruand and Gibson-Asner (1998), Baillie and Bollerslev (1990), Melvin and Hogan (1994) and Melvin and Melvin (2003).
} 
international stock markets changes over time and that these changes are affected by information (return) signals from yet other international stock markets that operate in intermediate time. In this study, we apply the FIT model which, as a new methodological tool, provides a unique framework that allows to investigate transmission of information and variation in the degree of interdependence of markets in their direct and indirect channels. The existing literature presents results based on models which can provide evidence about the relationships only in direct channels. Hence, the FIT model offers an advantage over other methodologies used in previous literature. We emphasize that this is a novel approach in studying the comovements of markets.

The remainder of the paper is organised as follows. Section 2 discusses the timeline and main events of the Global Financial Crisis, Section 3 reviews the foreign information transmission (FIT) model used to describe the effect of stock markets interdependence, Section 4 discusses the database, Section 5 presents empirical results and robustness analysis, Section 6 provides discussion of results and Section 7 concludes.

\section{Global Financial Crisis of 2007}

Melvin and Taylor (2009) provide a timeline of the most important events of the global financial crisis of 2007.

The sequence of events started in the fixed income securities markets, when it was apparent that the first problems emerged already in the early summer of 2007. In July 2007, volatility of equity markets increased. Melvin and Taylor (2009) state 
that "supposedly market-neutral equity portfolios suffered huge losses and it was common to hear people referring to a 'five (or larger) standard deviation event'“. In August 2007 the contagion from other asset classes spread to the currency market when carry trades started to unwind. As Melvin and Taylor (2009) document, the carry trade unwind, which occurred on 16 August 2007, was a devastating event for many investors. On that day the volatility of the currency market increased substantially.

The next stage of the financial crisis was in November 2007, when markets started to recognize problems with credit quality and firms faced difficulties in issuing asset-backed securities. The flight to quality has caused yields on Treasury Bills to fall. This was followed by the fall in commodity prices and deleveraging.

Year 2008 experienced bankruptcy of large financial institutions: Bear Stearns in March 2008 and Lehman Brothers in September 2008. Those events revealed severe problems with counterparty risk and liquidity and the dilemma regarding the "too big to fail" question faced by the policy-makers in central banks and governments.

In the next stages, the increased counterparty risk introduced lack of confidence in the ability of certain European countries to service their sovereign debt, which was increasing due to bank bailouts. This became the 'Eurozone crisis' unfolding for varying reasons across fiscal regimes of the Eurozone members. The downgrading of their sovereign debt rating made it even more costly to service their increasing debt levels causing widespread alarm in financial markets. The scramble for stability prompted wide governmental rescue plans associated with harsh austerity measures that inevitably introduced further risk due to political and financial 
uncertainty. Although this has been most pronounced in Greece, the range and scope of the repercussions of the financial crisis are still unfolding worldwide with substantial contagion and information transmission.

The GFC has had serious impact in Europe, however its consequences for the economies of Asian countries (and for the broader Asia - Pacific Basin region) were much more milder, since many of them avoided sovereign debt crisis and went through the global recession with only modest corrections of their business cycles.

\section{Foreign Information Transmission (FIT) methodology}

The methodology which we apply to describe the changes in interdependence of stock returns in their direct and indirect channels is the FIT model, introduced by Ibrahim and Brzeszczynski (2009). FIT is a conditional time-varying sequential information transmission methodology that describes the effect some variables have on the relationships that exist between other variables. In its simplest form, it is depicted as the following regression of $y$ on $x$ with time-varying coefficients $\alpha_{\mathrm{t}}$ and $\beta_{t}$ and an error term $w_{t}$ :

$$
y_{t}=\alpha_{t}+\beta_{t} x_{t}+w_{t} .
$$

Coefficient time varying dynamics are further assumed to depend on another, exogenous, variable, $z$, according to the following equations:

$$
\left(\alpha_{t+1}-\bar{\alpha}\right)=\left[a+b\left(z_{t}-\bar{z}\right)\right]\left(\alpha_{t}-\bar{\alpha}\right)+v_{\alpha, t+1},
$$

and

$$
\left(\beta_{t+1}-\bar{\beta}\right)=\left[\mathrm{c}+\mathrm{d}\left(\mathrm{z}_{\mathrm{t}}-\overline{\mathrm{z}}\right)\right]\left(\beta_{\mathrm{t}}-\bar{\beta}\right)+\mathrm{v}_{\beta, t+1},
$$


where $a, b, c$ and $d$ are constant coefficients; $\bar{z}, \bar{\alpha}$ and $\bar{\beta}$ are long-run average values or 'steady states' of the variable $z$ and the time-varying coefficients $\alpha_{t}$ and $\beta_{t}$; and $v_{\alpha, t+1}$ and $v_{\beta, t+1}$ are associated error terms. Conditional on $x_{t}$ and data observed through $t-1$, gathered in the vector $\mathbf{Y}_{\mathrm{t}-1}$, it is assumed that the vector of error terms $\left(v_{t+1} w_{t}\right)^{\prime}$ has a Gaussian distribution, viz.,

$$
\left[\begin{array}{c}
\mathbf{v}_{\mathrm{t}+1} \\
\mathrm{w}_{\mathrm{t}}
\end{array} \mid \mathrm{x}_{\mathrm{t}}, \mathbf{Y}_{\mathrm{t}-1}\right] \sim \mathrm{N}\left(\left[\begin{array}{l}
\mathbf{0} \\
0
\end{array}\right],\left[\begin{array}{cc}
\mathbf{Q} & \mathbf{0} \\
\mathbf{0}^{\prime} & \sigma_{\mathrm{w}}^{2}
\end{array}\right]\right),
$$

where $v_{t+1}=\left(v_{\alpha, t+1} v_{\beta, t+1}\right)^{\prime}$, and $\mathbf{Q}$ is a diagonal matrix. Stationarity is ensured if, for all $t=1, \ldots, T$, the eigenvalues of the matrix

$$
\mathbf{F}\left(\mathbf{z}_{\mathrm{t}}\right)=\left(\begin{array}{cc}
\mathrm{a}+\mathrm{b}\left(\mathrm{z}_{\mathrm{t}}-\overline{\mathrm{z}}\right) & 0 \\
0 & \mathrm{c}+\mathrm{d}\left(\mathrm{z}_{\mathrm{t}}-\overline{\mathrm{z}}\right)
\end{array}\right)
$$

are inside the unit circle. Full technical description, and details of the estimation procedure, are provided by Ibrahim and Brzeszczynski (2009).

The coefficient $\bar{\beta}$ captures effects in the direct channels of interdependence or information transmission from $x$ to $y$, while estimates of parameters $b$, and $d$ provide further information about the existence and nature of the interdependence through an indirect channel of information transmission from $z$.

The terms $\left(\alpha_{t}-\bar{\alpha}\right),\left(\beta_{t}-\bar{\beta}\right)$ and $\left(z_{t}-\bar{z}\right)$ are time-t (or day $\left.t\right)$ deviations of alpha, beta and the variable $z$ from their long-run averages, or steady states. Equations (2) and (3), therefore, describe how the level and intensity of the relationship between two markets change over time, and how these changes are affected by information from a third stock market, $z$. In particular, the coefficients $b$ and $d$ measure the impact of news that arise in the $z$ market on changes over time in 
the relationship between the $y$ and $x$ markets. In other words, they measure the effect of intermediate foreign, $z$, information on the interdependence relation between two markets. This represents the main incremental information that the FIT model provides over linear (OLS) regressions of $y$ on $x$. In particular, if $d$ is significantly positive (negative) then positive deviation of variable $z$ has an increasing (decreasing) effect on the intensity of the interdependence between market $x$ and market $y$. Parameter $d$ is of particular interest in this study since it measures the effect of the $z$ variable on the relation between variables $y$ and $x$. This is a novel approach since the measurement of such effects is not possible using other, more traditional, methodologies. ${ }^{2}$

In this study, we use different variables as $z$ in equations (2)-(3) in order to test interdependence of stock market returns in indirect channels. First, we use daily returns from the intermediate markets, which are active between the trading hours of markets $y$ and $x$. Second, we construct variables which may impact on the relationships between the largest stock trading centres, namely: (i) differentials in trading volume (turnover), (ii) differentials in stock price volatility and (iii) differentials in interest rate term spreads. Specifically, we use:

$$
z_{t}=\text { turnover }(y)_{t}-\text { turnover }(x)_{t}
$$

as volume differentials following the lag of markets $y$ and $x$ (e.g., if $y$ is the US market index DJIA on day $t$ and $x$ is Japanese market index TOPIX also on day $t$, then

\footnotetext{
${ }^{2}$ Another advantage of the FIT methodology is that it incorporates the phenomenon of volatility clustering that is often modelled by $\mathrm{ARCH}$ and stochastic volatility specifications. However, it does so through its formulation of the deterministic structure of the system (i.e., expected returns) rather than injecting heteroskedasticity through innovations or residuals (unexpected returns). Specifically, the term $\beta_{t} x_{t}$ of equation (1) is a product of an $\mathrm{AR}(1)$ process for $\beta_{t}$ with a random variable, $x_{t}$, and this is a type of specification shown by Granger and Machina (2002) to generate volatility drift, or clustering. Thus, conditional heteroskedasticity is structurally inherent.
} 
volume differential is equal to US volume on day $t$ minus Japan's volume also on day $t$, however if $y$ is the UK market index FTSE on day $t$ and $x$ is US market index DJIA on the previous day $t-1$, then volume differential is equal to UK volume on day $t$ minus US volume on day $t-1)$.

For the differential in volatility we use:

$$
z_{t}=\operatorname{volatility}(y)_{t}-\operatorname{volatility}(x)_{t}
$$

where volatility is defined as the amplitude of intra-daily changes in index values (i.e., daily $h i g h_{t}$ minus daily $l o w_{t}$ ) divided by their midpoint, viz.

$$
\text { volatility }=\left(\text { high }_{t}-\operatorname{low}_{t}\right) /\left(\left(h i g h_{t}+\operatorname{low}_{t}\right) / 2\right)
$$

where the spread follows the lag structure for $y$ and $x$, as described above. In other words, volatility is the spread between high and low index values as a percentage of the midpoint.

As the interest rate spread differentials (yield curve differentials) between two markets we use:

$$
z_{t}=\text { interest_rate spread }(y)_{t}-\text { interest_rate spread }(x)_{t}
$$

defined as the spread in market $y$ minus spread in market $x$, where spread equals the daily redemption yield of the 10-year bond minus the daily middle rate of the 1 month Treasury Bill from the respective two markets. Again, the model's lag structure for $y$ and $x$ is taken into account, as discussed above.

\section{Data}

Our database covers the period of 10 years from 1 July 2002 to 29 June 2012 and contains daily open, high, low and close levels of the DJIA, FTSE and TOPIX 
indices as well as trading volume and interest rate data for the US, UK and Japanese markets. The source of all data is Datastream.

This choice of period of time between July 2002 and June 2012 allows to divide it exactly in the middle when the GFC started in the equity markets in July 2007 and obtain two equal sub-samples of equal length of 5 years each (1 July $2002-29$ June 2007 and 2 July 2007 - 29 June 2012).

Figure 1 depicts distribution of daily returns of the DJIA, FTSE and TOPIX indices in the pre- and post-crisis periods and Table 1 presents basic statistics on these variables as well as on the volume differentials, volatility differentials and interest rate differentials between those markets. They illustrate the following patterns.

First, volatility of daily returns has increased in all three markets after the GFC. Standard deviations increased from 0.0077 to 0.0134 for DJIA, from 0.0105 to 0.0153 for FTSE and from 0.0085 to 0.0123 for TOPIX, which means percentage changes of: $+74 \%,+46 \%$ and $45 \%$, respectively.

Second, similar effect can be observed for volatility measured by the daily amplitude between high and low index levels, which has increased in all three markets after the GFC as well. It jumped from 0.0113 to 0.0167 for DJIA, from 0.0121 to 0.0186 for FTSE and from 0.0108 to 0.0137 for TOPIX, i.e. by $+48 \%$, $+54 \%$ and $+27 \%$.

Third, skewness of daily returns increased (i.e. became less negative) for the Japanese and the UK markets (from -0.48 to -0.23 and from -0.21 to -0.08 , respectively) but it decreased substantially in the USA (from 0.32 to -0.02 ). The return kurtosis increased for all markets, however most substantially for Japan. 
Fourth, trading volume (reported in Table 1 are the re-scaled values) has increased in Japan from 0.0144 to 0.0188 but it decreased in the UK market from 0.0016 to 0.0011 . In the USA it remained unchanged at the $0.0022-0.0023$ level.

Fifth, the volatility of the trading volume, as measured by its standard deviation, has increased from 0.0007 to 0.0010 in the USA but remained at a constant level of 0.0005 in the UK and it was slightly reduced from 0.0070 to 0.0064 in the Japanese market.

Sixth, the interest rates spread increased in the UK (from 0.0025 to 0.0183 ) and in the USA (from 0.0170 to 0.0251 ) but it narrowed in Japan (from 0.0131 to 0.0104 ).

In the next sections we investigate in more detail some of these effects between the pre- and post-crisis periods using the framework of the FIT methodology and analysis of direct and indirect channels of interdependence.

\section{Empirical Results}

In this section we present estimation results from the FIT models illustrating direct and indirect channels of interdependence of the three largest stock markets in New York, London and Tokyo. We report in turn estimation results when the $z$ variable in the FIT model is taken as stock index returns, differential in trading volume, differential in stock price volatility and differential in interest rate spreads.

Estimation results for the first model in Table 2, where return on the DJIA is the dependent variable $y$, return on the TOPIX is the independent variable $x$ and return on the FTSE is the variable of the intermediate market $z$, reveal that in the

whole period of 10 years the $\bar{\beta}$ is equal to 0.18 and significant at the $1 \%$ level. Most 
of the parameters from equations (2) and (3), i.e. $a, b$, and $c$, are also statistically significant, providing evidence about the existence of the indirect channel of returns transmission. However, the estimates of $\bar{\beta}$ in the two sub-samples in the pre- and post-crisis periods differ substantially and change from 0.14 to 0.25 (both statistically significant at the $1 \%$ level), respectively, which means that the relation between the Japanese index TOPIX as the influencer and the US index DJIA became nearly twice as strong as before the crisis.

Results for the second model in Table 2, where FTSE is the dependent variable $y$, DJIA is the independent variable $x$ (from the preceding day $t-1$ ) and TOPIX is now the variable of the intermediate market $z$, show the opposite effect: the estimate of $\bar{\beta}$ in the full sample is 0.31 (statistically significant at the $1 \%$ level), but it drops from 0.36 to 0.28 (both estimates statistically significant at the $1 \%$ level) between the two sub-samples. Again, most of the estimates of parameters from equations (2) and (3) are also statistically significant.

Estimates of the parameters in the third model presented in Table 2, where TOPIX is the dependent variable $y$, FTSE is the independent variable $x$ (from the preceding day $t-1$ ) and DJIA is now the variable of the intermediate market $z$ (also from the preceding day $t-1$ ), show that $\bar{\beta}$ is equal to 0.14 in the full sample (statistically significant at the $1 \%$ level) but it increases from 0.08 to 0.18 from the pre-crisis to post-crisis period (both estimates also statistically significant at the $1 \%$ level). The estimates of parameters from equations (2) and (3) are again mostly statistically significant.

The steady state estimates of alpha, $\bar{\alpha}$, reported in Table 2 are mostly insignificantly different from zero for all three relationships. 
In summary, the picture revealed by the analysis of $\bar{\beta}$ across all three models and in all samples clearly indicates that in all cases $\bar{\beta}$ is positive and significant. Furthermore, in the period before the global financial crisis (July 2002 - June 2007) the $\bar{\beta}$ differed in size between 0.08 to 0.36 , while in the period after the crisis (July 2007 - June 2012) its range narrowed and it has been spanning between 0.18 and 0.28. It also shows that the role the US market as the influencer (when it acts as the $x$ variable) diminishes, as captured by the $\bar{\beta}$ decreasing from 0.36 to 0.28 (i.e. by over 20\%), while London and Tokyo gained influence. Their $\bar{\beta}$ increases from 0.08 to 0.18 (i.e. by over $120 \%$ ) and from 0.14 to 0.25 (i.e. by nearly $80 \%$ ). This is one of the most important findings of this study. ${ }^{3}$

We now turn our attention to the analysis of estimates of parameters $a, b, c$ and $d$, which capture indirect channels of interdependence of stock markets, in particular we focus on parameter $d$ which measures the role of the intermediate market $z$ on the intensity of the relationship between markets $y$ and $x$.

In the meteor shower from Japan to USA, dubbed the DJIA model, the estimate of $d$ changes sign from positive 6.24 to negative -6.89 , but remains statistically significant at the $2 \%$ level. However, in the meteor shower from USA to UK, dubbed the FTSE model, it increases from negative -4.78 , and not statistically significant, to negative -11.54 and becomes significant at the $1 \%$ level. This means that the Japanese market index TOPIX gained significant influence in this indirect

\footnotetext{
${ }^{3}$ The change of the influence of those three markets is even more apparent when NIKKEI 225 index is used instead of TOPIX for the Japanese market. The $\bar{\beta}$ are $0.12,0.36$ and 0.08 in the DJIA, FTSE and NIKKEI models, respectively, in the pre-crisis period and they change to much more levelled values $0.26,0.27$ and 0.21 in the period after the GFC. Hence, the role of the London and Tokyo markets relative to the New York market seems to increase even more strongly using the NIKKEI index data.
} 
channel in the post-crisis period relative to the period before the crisis. The estimate of $d$ in the TOPIX model changes sign from -7.35 to 2.50 but remains insignificant in both sub-samples. This result indicates that the US market index DJIA does not have a significant influence in this indirect channel.

Overall, the estimation results from equations (2) - (3) confirm the significant role of the UK and Japanese market indices (with TOPIX clearly gaining significance in the post-crisis period) in the indirect channels, which supports the findings reported above about evolution of $\bar{\beta}$ that evidence role of those markets in direct channels.

We focus our attention now on analysis of other factors which may impact on the relationships between the largest stock trading centres, namely: (i) differentials in trading volume, (ii) differentials in stock price volatility and (iii) interest rate differentials.

Existing literature provides evidence about the role of trading volume in the relationships among stock markets and its importance in the explanation of the nature of information transmission effects (see e.g. Campbell, Grossman and Wang (1993), Wang (1994), Conrad, Hameed and Niden (1994), Llorente, Michaely, Saar and Wang (2002), Connolly and Stivers (2003), Gagnon and Karolyi (2006) and more recently Gagnon and Karolyi (2009) and Gębka (2012)).

We use volume of trade as a proxy of market activity. More specifically, we construct a variable defined as differential in the trading volume in two respective markets, in order to capture any effects that may arise when trading activity in one market is substantially higher (or lower) than in the other one in the analyzed pair. The hypothesis, which we test here, is whether an increased (or decreased) market 
activity in one market (first or second in the geographical sequence) affects the strength of the meteor shower (interdependence) between these two stock trading centres.

The variable defined as the differentials in stock market volatility (in form of the daily amplitude between high and low index levels) aims to capture any effects that may appear if volatility in one market is substantially higher (or lower) than in the other one in the analysed pair and we test the hypothesis whether such changes in volatilities affect the strength of the meteor shower (interdependence) between the two respective stock markets.

The interest rate differential for the two respective markets measures macroeconomic effects related to economic growth and its prospects in the future; more specifically to turning points in economic cycles. Harvey (1991), for example, shows that short-term rates exceeded long-term rates prior to the last five US recessions. This measure also partially captures distress in bond markets and is an integral element in the construction of indices that measure systemic risk (c.f., Wright, 2006).

Table 3 presents estimates from the models where differential in trading volume between markets $y$ and $x$ acts as the $z$ variable. A remarkable finding is that the estimate of the $d$ parameter in the model where $y$ is the DJIA index, $x$ is the TOPIX index and $\mathrm{z}$ is the differential in the daily volume of trade between New York and Tokyo stock exchanges, decreases in magnitude nearly five-fold from -53.31 to -11.68 and becomes insignificant in the post-crisis period (while the estimate -53.31 was statistically significant at the $1 \%$ level in the pre-crisis period). Exactly the same effect is observed in the second model where $y$ is the FTSE index, $x$ is the DJIA index (from previous day $t-1$ ) and $\mathrm{z}$ is the differential in the daily volume of trade 
between London and New York markets: it drops from 226.27 (the estimate is statistically significant the $1 \%$ level) to -61.57 (not significant). On the other hand, the estimate of $d$ in the third model where $y$ is the TOPIX index, $x$ is the FTSE index (from previous day $t-1)$ and $\mathrm{z}$ is the differential in the daily volume of trade between Tokyo and London markets, gains significance in the post-crisis period and the estimate increases two-fold from -10.08 (not significant) to -20.32 (significant at the $1 \%$ level).

These results provide evidence about the change of the relative strength of information about market activity in those three trading centres: the volume of trade in New York, and the resulting differential of volumes with the US market, seems to matter in the pre-crisis period but it is less relevant later in the post-crisis sample, while the differential of the volumes for UK and Japanese markets appears to gain importance in the post-crisis period.

Table 4 presents very similar picture about the relative change of roles of markets in New York, London and Tokyo from the point of view of the stock price volatility in the indirect channel of interdependence. In the first model of the DJIA index as $y$ with TOPIX as explanatory variable as $x$ and the volatility differentials between New York and Tokyo markets as $z$, the estimate of parameter $d$ remains significant at the $1 \%$ level but it changes in magnitude from -19.70 to -12.29 between the pre-crisis and post-crisis periods. In the second model of the FTSE index as $y$ with DJIA as $x$ and the volatility differentials between London and New York markets as $z$, the estimate of parameter $d$ drops over four-fold from 14.29 (statistically significant at the $1 \%$ level) to 3.33 (and not statistically significant). However, in the third model of the TOPIX as $y$ with FTSE as $x$ and the volatility differentials between 
Tokyo and London markets as $z$, the estimate of parameter $d$ strengthens from -7.11 (and not statistically significant) to -15.65 (and significant at the $1 \%$ level).

Hence, the findings from the models with variable defined as excess volatility between given markets seem to paint the same picture as the results from models with excess volume of trade variable in Table 3, i.e. that the role of the US market weakened in the post-crisis period and the other two markets in Japan and London strengthened their influence relative to each other and to the US.

Finally, Table 5 shows results for models with interest rate differentials. It demonstrates no evidence about significance of the $d$ parameter in any of the relationships (with some significance of parameters $a$ and $b$ ). Hence, the interest rate differentials do not seem to have a significant impact on the relationships between those three stock markets.

Overall, we find evidence that trading volume differentials and volatility differentials do affect the interdependence relations between major stock trading centres in New York, London and Tokyo but no evidence about the impact of the interest rates differentials. Moreover, our results are robust to different models' specifications since $\bar{\beta}$ did not change materially in models that have any of these variables.

The results also clearly indicate that the role of the US market as the influencer of the stock price movements in other markets has weakened after the GFC in 2007 while at the same time the role of the other two trading centres in the UK and Japan has strengthened. 


\section{Discussion}

A possible explanation of our findings may be related to the fact that the GFC moved to Europe after 2007 when many south European countries experienced macroeconomic problems and faced serious debt crisis. This would be consistent with this part of our results, which clearly indicate that the role of Europe, as represented in our models by the London stock market index returns, has strengthened in the post-crisis period.

The findings presented in this study may, however, reflect a different phenomenon: they may be indicative of the existence of broader macro-economic trends on the global scale. For example, a recent OECD report (2012), published on 9 November 2012, argues that the world will experience "dramatic shift" in balance of economic power in the near future. The OECD predicts that China will overtake the USA in terms of the GDP by as early as 2016 , which means that the USA will then lose its leading position as the world's largest economy. Furthermore, the OECD data show that the US share in global GDP (calculated as sum of GDP for 34 OECD and 8 non-OECD G20 countries) will drop from 23\% in 2011 to $18 \%$ by 2030 (although other economic superpowers, such as Japan and countries in the Euro area will also experience a decrease in their share of the world GDP). Those macroeconomic trends are consistent with our findings about the diminishing role of the US market as the influencer of the stock price movements in other markets.

As Figure 1 illustrates, the changes in distributions of returns between the preand post-crisis periods (lower peaks and fatter tails) are similar across all three indices, but the change is most prominent in the case of the US market, which is supportive of the rest of our results. In addition, Figure 1 and Table 1 show that 
return kurtosis increased most substantially for Japan, which could be related to the flight of capital to safer Japan for the positive side of returns and fears of trade effects for the negative side of returns. This effect is consistent with the story about the change of balance of economic power across countries and, possibly also, across the entire geographical regions.

\section{Conclusions}

We provided evidence about evolution of interdependence of major stock markets in New York, London and Tokyo before and after the Global Financial Crisis. Using the framework of the Foreign Information Transmission (FIT) we investigated their relations with each other in direct and indirect channels and we also analysed the impact of other factors, such as differentials in trading volume, differentials in stock price volatility and interest rate differentials.

We find that our results are robust to different models' specifications and they clearly indicate that the role of the US market as the influencer of the stock price movements in other markets has weakened after the GFC in 2007 while the role of the other two trading centres in the UK and Japan has strengthened.

An explanation related to the shift in balance of economic powers between countries, as predicted by the OECD and other international institutions, calls for further research involving analyses of interdependence and changing roles of other stock trading centres, including those which are still considered today as emerging markets. 
Figure 1. Distribution of daily returns in the pre- and post-crisis periods.

A. Japan (TOPIX)

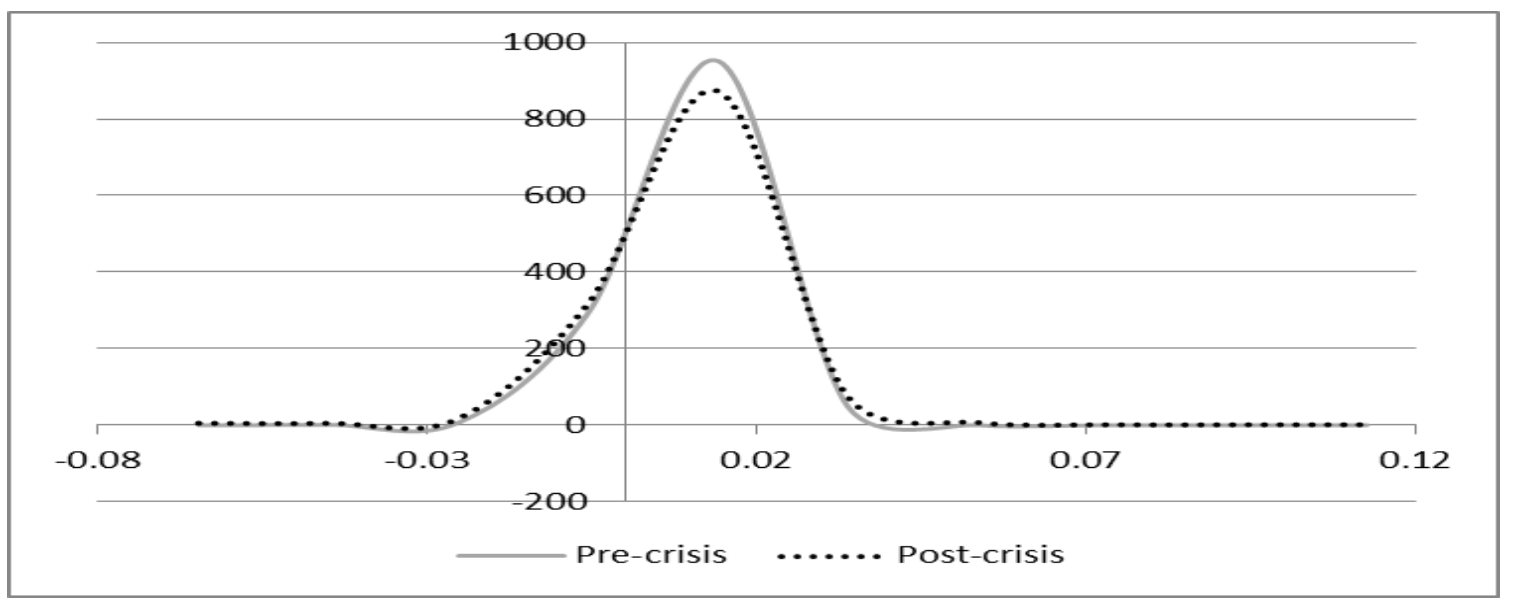

B. UK (FTSE 100)

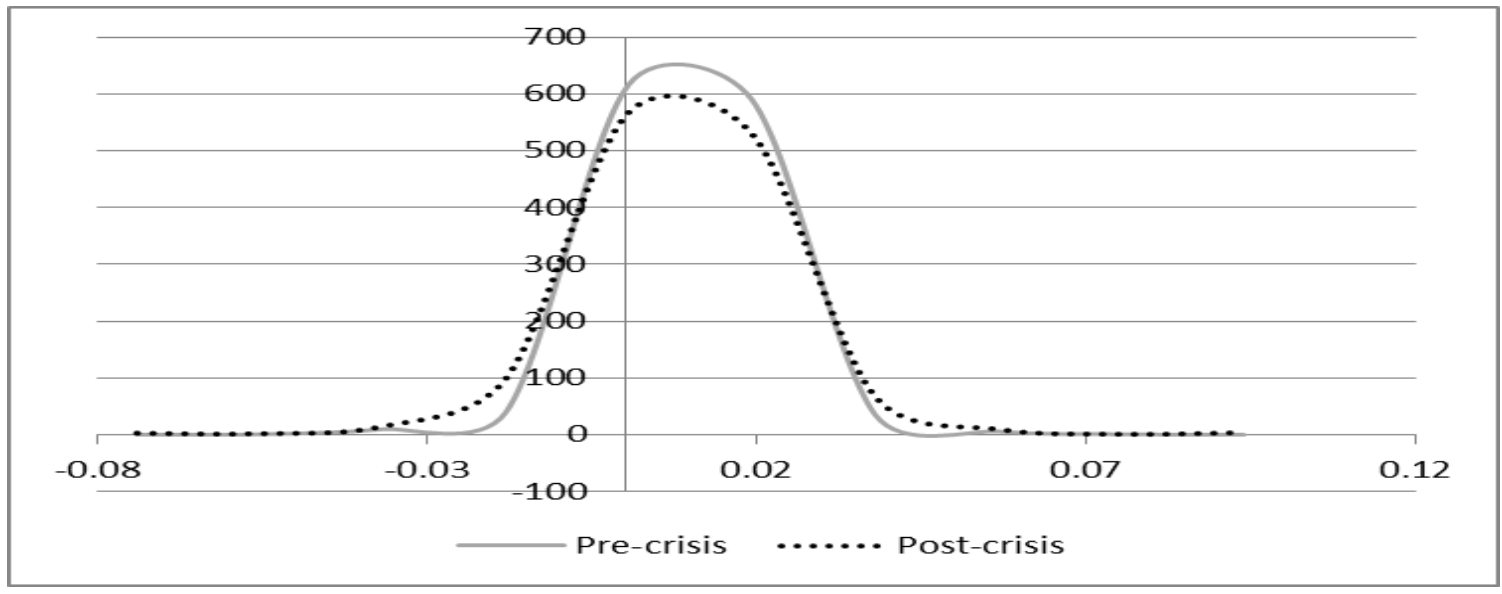

C. USA (Dow Jones Industrial Average)

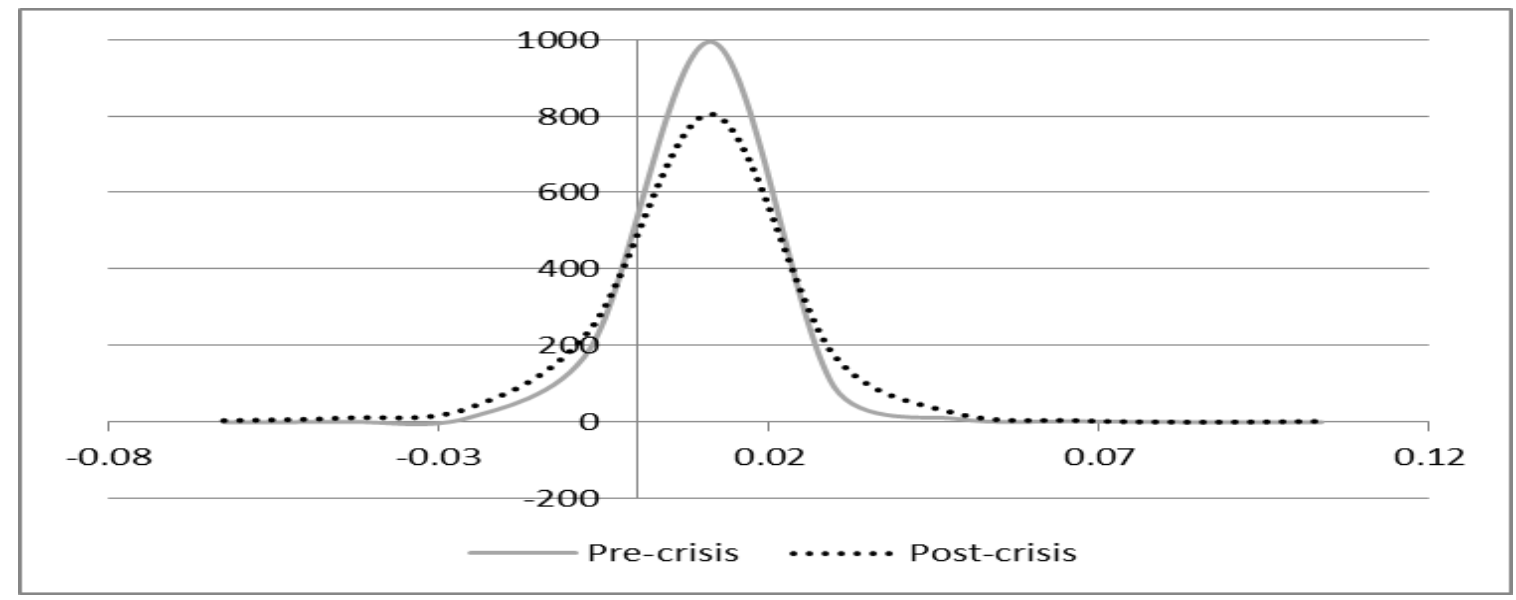

Notes:

The graphs present the frequency distribution of continuously-compounded open-to-close daily returns. The $y$-axis is the frequency count, and the $x$-axis is the returns. 
Table 1. Descriptive statistics.

\begin{tabular}{|l|r|r|r|r|r|r|r|r|r|r|r|r|}
\cline { 2 - 12 } All Sample & \multicolumn{1}{l|}{$J P p c H L$} & \multicolumn{1}{|l}{$J P I n C O$} & $J P V$ & $J P S$ & UKpcHL & UKInCO & UKV & UKS & USpcHL & USInCO & USV & USS \\
\hline Mean & 0.0123 & -0.0005 & 0.0166 & 0.0117 & 0.0154 & 0.0001 & 0.0014 & 0.0104 & 0.0140 & 0.0002 & 0.0023 & 0.0211 \\
\hline Median & 0.0106 & 0.0000 & 0.0173 & 0.0117 & 0.0123 & 0.0000 & 0.0014 & 0.0072 & 0.0113 & 0.0004 & 0.0022 & 0.0240 \\
\hline Std Dev & 0.0091 & 0.0106 & 0.0071 & 0.0028 & 0.0114 & 0.0131 & 0.0006 & 0.0140 & 0.0113 & 0.0125 & 0.0009 & 0.0123 \\
\hline Kurtosis & 29.8140 & 12.7625 & 1.2689 & -0.1021 & 9.6066 & 6.7024 & 1.0296 & -1.1617 & 17.0275 & 8.7146 & 2.8913 & -0.7081 \\
\hline Skewness & 3.7296 & -0.3213 & -0.1822 & 0.2415 & 2.4113 & -0.1363 & 0.1455 & 0.4651 & 3.1811 & 0.0314 & 0.5939 & -0.6576 \\
\hline Range & 0.1357 & 0.1969 & 0.0578 & 0.0154 & 0.1074 & 0.1865 & 0.0045 & 0.0499 & 0.1214 & 0.1848 & 0.0072 & 0.0475 \\
\hline Minimum & 0.0000 & -0.0844 & 0.0000 & 0.0042 & 0.0000 & -0.0927 & 0.0000 & -0.0118 & 0.0000 & -0.0810 & 0.0000 & -0.0078 \\
\hline Maximum & 0.1357 & 0.1126 & 0.0578 & 0.0196 & 0.1074 & 0.0938 & 0.0045 & 0.0381 & 0.1214 & 0.1038 & 0.0072 & 0.0397 \\
\hline Count & 2602 & 2602 & 2602 & 2602 & 2602 & 2602 & 2602 & 2602 & 2602 & 2602 & 2602 & 2602 \\
\hline
\end{tabular}

\begin{tabular}{|l|r|r|r|r|r|r|r|r|r|r|r|r|}
\cline { 2 - 13 } \multicolumn{1}{l|}{ Pre-crisis } & $J P p C H L$ & $J P I n C O$ & $J P V$ & $J P S$ & $U K P C H L$ & $U K I n C O$ & $U K V$ & $U K S$ & USPCHL & USInCO & USV & USS \\
\hline Mean & 0.0108 & -0.0004 & 0.0144 & 0.0131 & 0.0121 & 0.0003 & 0.0016 & 0.0025 & 0.0113 & 0.0004 & 0.0023 & 0.0170 \\
\hline Median & 0.0098 & 0.0000 & 0.0143 & 0.0135 & 0.0094 & 0.0003 & 0.0016 & 0.0008 & 0.0093 & 0.0004 & 0.0023 & 0.0210 \\
\hline Std Dev & 0.0062 & 0.0085 & 0.0070 & 0.0030 & 0.0094 & 0.0105 & 0.0005 & 0.0055 & 0.0077 & 0.0093 & 0.0007 & 0.0136 \\
\hline Kurtosis & 4.7562 & 2.0378 & 0.8426 & 0.4265 & 8.8972 & 5.5324 & 3.5437 & -1.2011 & 11.1378 & 5.1620 & 4.6303 & -1.3709 \\
\hline Skewness & 1.3100 & -0.4783 & 0.3488 & -0.6091 & 2.5172 & -0.2090 & -0.4782 & 0.3838 & 2.4291 & 0.3183 & -0.1282 & -0.2373 \\
\hline Range & 0.0543 & 0.0817 & 0.0456 & 0.0154 & 0.0789 & 0.1149 & 0.0045 & 0.0205 & 0.0851 & 0.1092 & 0.0072 & 0.0475 \\
\hline Minimum & 0.0000 & -0.0522 & 0.0000 & 0.0042 & 0.0000 & -0.0559 & 0.0000 & -0.0059 & 0.0000 & -0.0471 & 0.0000 & -0.0078 \\
\hline Maximum & 0.0543 & 0.0296 & 0.0456 & 0.0196 & 0.0789 & 0.0590 & 0.0045 & 0.0146 & 0.0851 & 0.0621 & 0.0072 & 0.0397 \\
\hline Count & 1301 & 1301 & 1301 & 1301 & 1301 & 1301 & 1301 & 1301 & 1301 & 1301 & 1301 & 1301 \\
\hline
\end{tabular}

\begin{tabular}{|l|r|r|r|r|r|r|r|r|r|r|r|r|}
\cline { 2 - 12 } Post-crisis & $J P p c H L$ & $J P I n C O$ & $J P V$ & $J P S$ & $U K p c H L$ & UKInCO & UKV & UKS & USpcHL & USInCO & USV & USS \\
\hline Mean & 0.0137 & -0.0007 & 0.0188 & 0.0104 & 0.0186 & -0.0002 & 0.0011 & 0.0183 & 0.0167 & 0.0001 & 0.0022 & 0.0251 \\
\hline Median & 0.0114 & -0.0001 & 0.0193 & 0.0103 & 0.0157 & 0.0000 & 0.0010 & 0.0237 & 0.0135 & 0.0004 & 0.0020 & 0.0263 \\
\hline Std Dev & 0.0110 & 0.0123 & 0.0064 & 0.0016 & 0.0124 & 0.0153 & 0.0005 & 0.0154 & 0.0134 & 0.0150 & 0.0010 & 0.0093 \\
\hline Kurtosis & 24.3219 & 13.0563 & 4.1865 & -0.8677 & 9.4756 & 5.6027 & 2.7686 & -1.0353 & 13.1472 & 7.0332 & 2.1671 & 0.1964 \\
\hline Skewness & 3.6425 & -0.2269 & -0.7459 & -0.0148 & 2.3775 & -0.0819 & 0.8554 & -0.6646 & 2.9094 & -0.0233 & 0.9744 & -0.8232 \\
\hline Range & 0.1357 & 0.1969 & 0.0578 & 0.0076 & 0.1074 & 0.1865 & 0.0039 & 0.0499 & 0.1214 & 0.1848 & 0.0067 & 0.0432 \\
\hline Minimum & 0.0000 & -0.0844 & 0.0000 & 0.0065 & 0.0000 & -0.0927 & 0.0000 & -0.0118 & 0.0000 & -0.0810 & 0.0000 & -0.0036 \\
\hline Maximum & 0.1357 & 0.1126 & 0.0578 & 0.0141 & 0.1074 & 0.0938 & 0.0039 & 0.0381 & 0.1214 & 0.1038 & 0.0067 & 0.0396 \\
\hline Count & 1301 & 1301 & 1301 & 1301 & 1301 & 1301 & 1301 & 1301 & 1301 & 1301 & 1301 & 1301 \\
\hline
\end{tabular}

Notes:

Prefixes $J P=$ Japan, $U K=$ United Kingdom, $U S=$ United States. $p c H L=$ percentage difference between daily High $(H)$ and daily Low $(\mathrm{L})=(\mathrm{H}-\mathrm{L}) /(\mathrm{H}+\mathrm{L}) / 2 ; \operatorname{InCO}=$ continuous compounded open-close returns; $V=$ Volume rescaled by dividing by 100 for US and Japan and by 1000 for UK; $S=$ Interest rate spread = YTM of 10Yr Bonds - Middle Rate of 1M TBills, rescaled by dividing by 100. Tabulated Descriptive Statistics are of the rescaled variables. The sample period is 1 July 2002 through 29 June 2012, divided equally around 29 June 2007 for pre-crisis and post-crisis sub-samples. 
Table 2. Estimation results from simple meteor shower models.

\begin{tabular}{|c|c|c|c|c|c|c|c|c|c|}
\hline & \multicolumn{9}{|c|}{ Meteor shower from Japan(t) to USA(t) with UK(t) as variable $z$} \\
\hline & \multicolumn{3}{|c|}{ All sample period } & \multicolumn{3}{|c|}{ Pre-crisis } & \multicolumn{3}{|c|}{ Post-crisis } \\
\hline & Estimate & $t$-stat & $p$-value & Estimate & $t$-stat & $p$-value & Estimate & $t$-stat & $p$-value \\
\hline $\bar{\alpha}$ & 0.0002 & 1.0983 & 0.14 & 0.0005 & 1.8225 & 0.03 & 0.0001 & 0.1480 & 0.44 \\
\hline $\bar{\beta}$ & 0.1836 & 6.2441 & 0.00 & 0.1387 & 4.3101 & 0.00 & 0.2511 & 5.4599 & 0.00 \\
\hline$\sigma_{\alpha}$ & 0.0018 & 12.9325 & 0.00 & 0.0006 & 4.3053 & 0.00 & -0.0051 & -7.0136 & 0.00 \\
\hline$\sigma_{\beta}$ & 0.6035 & 22.5829 & 0.00 & 0.2572 & 5.8836 & 0.00 & 0.6280 & 12.8958 & 0.00 \\
\hline$\sigma_{\mathrm{ww}}$ & 0.0099 & 97.6803 & 0.00 & 0.0084 & 62.4628 & 0.00 & 0.0107 & 23.4792 & 0.00 \\
\hline$a$ & -0.7771 & -37.0491 & 0.00 & -0.8298 & -18.4004 & 0.00 & -0.5700 & -15.3815 & 0.00 \\
\hline$b$ & 23.4517 & 38.4705 & 0.00 & -41.0714 & -27.5942 & 0.00 & 16.6404 & 9.8606 & 0.00 \\
\hline c & -0.2246 & -3.3335 & 0.00 & -0.7052 & -10.0503 & 0.00 & -0.1765 & -1.5610 & 0.06 \\
\hline$d$ & -3.2727 & -1.9480 & 0.03 & 6.2416 & 3.0761 & 0.00 & \begin{tabular}{|c|}
-6.8854 \\
\end{tabular} & \begin{tabular}{|c|}
-2.1045 \\
\end{tabular} & 0.02 \\
\hline
\end{tabular}

\begin{tabular}{|c|c|c|c|c|c|c|c|c|c|}
\hline & \multicolumn{9}{|c|}{ Meteor shower from USA $(\mathrm{t}-1)$ to $\mathrm{UK}(\mathrm{t})$ with Japan $(\mathrm{t})$ as variable $z$} \\
\hline $\bar{\alpha}$ & 0.0000 & 0.0577 & 0.48 & 0.0002 & 0.8535 & 0.20 & -0.0002 & -0.6074 & 0.27 \\
\hline $\bar{\beta}$ & 0.3144 & 11.2063 & 0.00 & 0.3594 & 8.6322 & 0.00 & 0.2769 & 7.3008 & 0.00 \\
\hline$\sigma_{\alpha}$ & -0.0040 & -13.9416 & 0.00 & -0.0026 & -7.8415 & 0.00 & 0.0039 & 9.3537 & 0.00 \\
\hline$\sigma_{\beta}$ & 0.6042 & 26.4422 & 0.00 & 0.6629 & 20.4075 & 0.00 & 0.4798 & 13.5683 & 0.00 \\
\hline$\sigma_{\mathrm{w}}$ & 0.0087 & 42.7617 & 0.00 & 0.0067 & 36.0750 & 0.00 & 0.0113 & 35.3774 & 0.00 \\
\hline$a$ & -0.7041 & -31.8284 & 0.00 & -0.8089 & -29.0362 & 0.00 & -0.7177 & -24.2453 & 0.00 \\
\hline$b$ & 18.2859 & 15.5125 & 0.00 & 23.5457 & 6.5637 & 0.00 & 18.2655 & 11.6728 & 0.00 \\
\hline$c$ & 0.0198 & 0.3179 & 0.38 & 0.0647 & 0.8013 & 0.21 & 0.0266 & 0.2660 & 0.40 \\
\hline$d$ & -5.1242 & -2.3849 & 0.01 & -4.7773 & -0.6517 & 0.26 & -11.5380 & -4.3548 & 0.00 \\
\hline
\end{tabular}

\begin{tabular}{|c|c|c|c|c|c|c|c|c|c|}
\hline & \multicolumn{9}{|c|}{ Meteor shower from UK(t-1) to Japan(t) with USA(t-1) as variable $z$} \\
\hline $\bar{\alpha}$ & -0.0005 & -2.5759 & 0.00 & -0.0004 & -1.5233 & 0.06 & -0.0006 & -2.0694 & 0.02 \\
\hline $\bar{\beta}$ & 0.1449 & 6.4979 & 0.00 & 0.0765 & 2.7855 & 0.00 & 0.1773 & 5.7030 & 0.00 \\
\hline$\sigma_{\alpha}$ & -0.0059 & -16.1238 & 0.00 & 0.0009 & 1.0329 & 0.15 & 0.0070 & 13.6343 & 0.00 \\
\hline$\sigma_{\beta}$ & 0.3913 & 22.8064 & 0.00 & 0.2181 & 5.1348 & 0.00 & 0.4159 & 17.3103 & 0.00 \\
\hline$\sigma_{\mathrm{w}}$ & 0.0061 & 15.3814 & 0.00 & 0.0081 & 44.0365 & 0.00 & 0.0060 & 9.0601 & 0.00 \\
\hline$a$ & -0.0776 & -3.6146 & 0.00 & -0.1083 & -0.9481 & 0.17 & -0.0858 & -3.3843 & 0.00 \\
\hline$b$ & 24.4479 & 27.2286 & 0.00 & 53.7343 & 6.9292 & 0.00 & 23.5235 & 21.5588 & 0.00 \\
\hline c & 0.1480 & 2.7491 & 0.00 & 0.0025 & 0.0071 & 0.50 & 0.1752 & 2.5822 & 0.00 \\
\hline$d$ & 2.7648 & 1.9094 & 0.03 & -7.3544 & -0.5368 & 0.30 & 2.4980 & 1.3218 & 0.09 \\
\hline
\end{tabular}


Table 3. Estimation results from meteor shower models with volume differential as indirect information channel.

\begin{tabular}{|c|c|c|c|c|c|c|c|c|c|}
\hline & \multicolumn{9}{|c|}{ Meteor shower from Japan(t) to USA(t) with volume differential as variable $z$} \\
\hline & \multicolumn{3}{|c|}{ All sample period } & \multicolumn{3}{|c|}{ Pre-crisis } & \multicolumn{3}{|c|}{ Post-crisis } \\
\hline & Estimate & $t$-stat & $p$-value & Estimate & $t$-stat & $p$-value & Estimate & t-stat & $p$-value \\
\hline $\bar{\alpha}$ & 0.0003 & 1.3648 & 0.09 & 0.0005 & 1.8470 & 0.03 & 0.0002 & 0.6714 & 0.25 \\
\hline $\bar{\beta}$ & 0.2005 & 7.1183 & 0.00 & 0.1356 & 4.1862 & 0.00 & 0.2576 & 5.8065 & 0.00 \\
\hline$\sigma_{\alpha}$ & 0.0082 & 6.9335 & 0.00 & -0.0019 & -6.4560 & 0.00 & -0.0121 & -5.3624 & 0.00 \\
\hline$\sigma_{\beta}$ & 0.5187 & 19.5177 & 0.00 & 0.3307 & 11.5928 & 0.00 & 0.5688 & 11.9958 & 0.00 \\
\hline$\sigma_{\mathrm{w}}$ & 0.0066 & 4.5138 & 0.00 & 0.0079 & 57.4169 & 0.00 & 0.0033 & 0.4153 & 0.34 \\
\hline$a$ & -0.2295 & -4.7261 & 0.00 & -0.5065 & -3.6012 & 0.00 & -0.2226 & -3.4189 & 0.00 \\
\hline$b$ & 12.7842 & 4.0948 & 0.00 & -48.4804 & -2.9762 & 0.00 & 10.8405 & 2.5979 & 0.00 \\
\hline$c$ & -0.3624 & -6.6706 & 0.00 & -0.3715 & -2.8250 & 0.00 & -0.3121 & -3.1070 & 0.00 \\
\hline$d$ & -26.1885 & -5.3183 & 0.00 & -53.3102 & -3.7751 & 0.00 & -11.6843 & -0.7033 & 0.24 \\
\hline
\end{tabular}

\begin{tabular}{|c|c|c|c|c|c|c|c|c|c|}
\hline & \multicolumn{9}{|c|}{ Meteor shower from USA(t-1) to UK(t) with volume differential as variable $z$} \\
\hline $\bar{\alpha}$ & - & - & - & - & - & - & - & - & - \\
\hline $\bar{\beta}$ & 0.3588 & 12.6746 & 0.00 & 0.4016 & 10.1673 & 0.00 & 0.3686 & 10.0256 & 0.00 \\
\hline$\sigma_{\alpha}$ & -0.0073 & -15.8832 & 0.00 & -0.0050 & -13.5769 & 0.00 & 0.0123 & 12.7148 & 0.00 \\
\hline$\sigma_{\beta}$ & 0.6029 & 28.0260 & 0.00 & 0.6394 & 17.9267 & 0.00 & 0.4658 & 12.5450 & 0.00 \\
\hline$\sigma_{\mathrm{w}}$ & 0.0066 & 15.2597 & 0.00 & 0.0054 & 20.4326 & 0.00 & 0.0030 & 0.8322 & 0.20 \\
\hline$a$ & -0.4778 & -12.8243 & 0.00 & -0.6056 & -14.4199 & 0.00 & -0.3013 & -6.2101 & 0.00 \\
\hline$b$ & 51.9362 & 2.3901 & 0.01 & 5.0628 & 0.1630 & 0.44 & -10.2539 & -0.3340 & 0.37 \\
\hline$c$ & -0.0307 & -0.4192 & 0.34 & -0.0172 & -0.2314 & 0.41 & -0.0832 & -0.6499 & 0.26 \\
\hline$d$ & -24.4888 & -0.3946 & 0.35 & 226.2657 & 2.4713 & 0.01 & -61.5712 & -0.6572 & 0.26 \\
\hline
\end{tabular}

\begin{tabular}{|c|c|c|c|c|c|c|c|c|c|}
\hline & \multicolumn{9}{|c|}{ Meteor shower from UK(t-1) to Japan(t) with volume differential as variable $z$} \\
\hline $\bar{\alpha}$ & - & - & - & - & - & - & - & - & - \\
\hline $\bar{\beta}$ & 0.1341 & 6.3506 & 0.00 & 0.0749 & 2.7008 & 0.00 & 0.1637 & 5.5703 & 0.00 \\
\hline$\sigma_{\alpha}$ & 0.0021 & 5.7243 & 0.00 & 0.0053 & 0.9920 & 0.16 & -0.0021 & -5.1466 & 0.00 \\
\hline$\sigma_{\beta}$ & 0.3946 & 21.9881 & 0.00 & 0.2395 & 5.8313 & 0.00 & 0.4134 & 17.0622 & 0.00 \\
\hline$\sigma_{\mathrm{w}}$ & 0.0084 & 72.6140 & 0.00 & 0.0061 & 1.3101 & 0.10 & 0.0093 & 60.8233 & 0.00 \\
\hline$a$ & -0.5770 & -7.7565 & 0.00 & -0.0477 & -0.4312 & 0.33 & -0.7491 & -17.9063 & 0.00 \\
\hline$b$ & -25.3034 & -4.7005 & 0.00 & -14.1643 & -0.5349 & 0.30 & -23.8128 & -3.4987 & 0.00 \\
\hline$c$ & -0.0145 & -0.1493 & 0.44 & -0.0060 & -0.0188 & 0.49 & -0.0093 & -0.0830 & 0.47 \\
\hline$d$ & -15.9475 & -2.1415 & 0.02 & -10.0804 & -0.2640 & 0.40 & -20.3194 & -2.2851 & 0.01 \\
\hline
\end{tabular}


Table 4. Estimation results from meteor shower models with volatility differential as indirect information channel.

\begin{tabular}{|c|c|c|c|c|c|c|c|c|c|}
\hline & \multicolumn{9}{|c|}{ Meteor shower from Japan(t) to USA(t) with volatility differential as variable $z$} \\
\hline & \multicolumn{3}{|c|}{ All sample period } & \multicolumn{3}{|c|}{ Pre-crisis } & \multicolumn{3}{|c|}{ Post-crisis } \\
\hline & Estimate & $t$-stat & $p$-value & Estimate & $t$-stat & $p$-value & Estimate & $t$-stat & $p$-value \\
\hline $\bar{\alpha}$ & 0.0003 & 1.5654 & 0.06 & 0.0004 & 1.7073 & 0.04 & 0.0003 & 1.0586 & 0.14 \\
\hline $\bar{\beta}$ & 0.2092 & 7.2927 & 0.00 & 0.1313 & 3.9674 & 0.00 & 0.2761 & 6.2465 & 0.00 \\
\hline$\sigma_{\alpha}$ & 0.0036 & 10.2358 & 0.00 & 0.0012 & 4.9380 & 0.00 & 0.0119 & 7.2910 & 0.00 \\
\hline$\sigma_{\beta}$ & 0.5500 & 19.8669 & 0.00 & 0.3383 & 11.3426 & 0.00 & 0.5640 & 13.1382 & 0.00 \\
\hline$\sigma_{\mathrm{w}}$ & 0.0096 & 62.2418 & 0.00 & 0.0082 & 57.0018 & 0.00 & 0.0033 & 0.5746 & 0.28 \\
\hline$a$ & -0.3378 & -8.3012 & 0.00 & -0.7024 & -11.6421 & 0.00 & -0.3531 & -5.5646 & 0.00 \\
\hline$b$ & -23.7726 & -27.5572 & 0.00 & -19.6427 & -5.2904 & 0.00 & 9.5155 & 7.0992 & 0.00 \\
\hline$c$ & -0.2793 & -3.3578 & 0.00 & -0.4171 & -4.1935 & 0.00 & -0.2920 & -2.9678 & 0.00 \\
\hline$d$ & -8.4841 & -2.7924 & 0.00 & -19.7051 & -3.8776 & 0.00 & -12.2876 & -3.4591 & 0.00 \\
\hline
\end{tabular}

\begin{tabular}{|c|c|c|c|c|c|c|c|c|c|}
\hline & \multicolumn{9}{|c|}{ Meteor shower from USA(t-1) to UK(t) with volatility differential as variable $z$} \\
\hline $\bar{\alpha}$ & 0.0000 & -0.0470 & 0.48 & 0.0001 & 0.5804 & 0.28 & - & - & - \\
\hline $\bar{\beta}$ & 0.3660 & 13.3603 & 0.00 & 0.4039 & 9.8774 & 0.00 & 0.3686 & 10.2344 & 0.00 \\
\hline$\sigma_{\alpha}$ & -0.0077 & -19.3258 & 0.00 & 0.0052 & 17.1661 & 0.00 & 0.0123 & 10.8362 & 0.00 \\
\hline$\sigma_{\beta}$ & 0.5969 & 28.0294 & 0.00 & 0.6500 & 18.7637 & 0.00 & 0.4617 & 12.3395 & 0.00 \\
\hline$\sigma_{\mathrm{w}}$ & 0.0063 & 15.1863 & 0.00 & 0.0053 & 20.0270 & 0.00 & 0.0031 & 0.7353 & 0.23 \\
\hline$a$ & -0.4047 & -11.0453 & 0.00 & -0.4603 & -10.5594 & 0.00 & -0.2790 & -5.6314 & 0.00 \\
\hline$b$ & -8.2267 & -4.3594 & 0.00 & -19.1949 & -7.4390 & 0.00 & -2.9777 & -1.2386 & 0.11 \\
\hline c & -0.0465 & -0.7515 & 0.23 & -0.1368 & -1.2758 & 0.10 & -0.0684 & -0.6282 & 0.26 \\
\hline$d$ & 3.8298 & 1.3247 & 0.09 & 14.2875 & 3.1940 & 0.00 & 3.3292 & 0.6441 & 0.26 \\
\hline
\end{tabular}

\begin{tabular}{|c|c|c|c|c|c|c|c|c|c|}
\hline & \multicolumn{9}{|c|}{ Meteor shower from UK(t-1) to Japan(t) with volatility differential as variable $z$} \\
\hline $\bar{\alpha}$ & -0.0005 & -2.8130 & 0.00 & -0.0004 & -1.4649 & 0.07 & -0.0007 & -2.4218 & 0.01 \\
\hline $\bar{\beta}$ & 0.1340 & 6.2109 & 0.00 & 0.0788 & 2.7083 & 0.00 & 0.1669 & 5.1539 & 0.00 \\
\hline$\sigma_{\alpha}$ & 0.0009 & 5.2872 & 0.00 & 0.0040 & 4.0831 & 0.00 & 0.0062 & 10.9332 & 0.00 \\
\hline$\sigma_{\beta}$ & 0.4167 & 23.0153 & 0.00 & 0.2557 & 6.2934 & 0.00 & 0.4587 & 19.3982 & 0.00 \\
\hline$\sigma_{\mathrm{w}}$ & 0.0084 & 80.3583 & 0.00 & 0.0069 & 11.2769 & 0.00 & 0.0064 & 10.9575 & 0.00 \\
\hline$a$ & -0.9085 & -90.1174 & 0.00 & 0.0977 & 1.1731 & 0.12 & -0.4919 & -11.7562 & 0.00 \\
\hline$b$ & 11.8575 & 12.1314 & 0.00 & -29.5919 & -4.4048 & 0.00 & 18.3149 & 10.8497 & 0.00 \\
\hline$c$ & -0.0221 & -0.3674 & 0.36 & 0.0519 & 0.1650 & 0.43 & 0.1027 & 1.7096 & 0.04 \\
\hline$d$ & -9.5213 & -5.4550 & 0.00 & -7.1090 & -0.3812 & 0.35 & -15.6472 & -9.6614 & 0.00 \\
\hline
\end{tabular}


Table 5. Estimation results from meteor shower models with interest rate spread differential as indirect information channel.

\begin{tabular}{|c|c|c|c|c|c|c|c|c|c|}
\hline & \multicolumn{9}{|c|}{ Meteor shower from Japan(t) to USA(t) with interest differential as variable $z$} \\
\hline & \multicolumn{3}{|c|}{ All sample period } & \multicolumn{3}{|c|}{ Pre-crisis } & \multicolumn{3}{|c|}{ Post-crisis } \\
\hline & Estimate & $t$-stat & $p$-value & Estimate & $t$-stat & $p$-value & Estimate & $t$-stat & $p$-value \\
\hline $\bar{\alpha}$ & 0.0033 & 1.4666 & 0.07 & 0.0042 & 1.6840 & 0.05 & 0.0026 & 0.7640 & 0.22 \\
\hline $\bar{\beta}$ & 0.2019 & 7.4835 & 0.00 & 0.1421 & 4.3218 & 0.00 & 0.2566 & 6.4128 & 0.00 \\
\hline$\sigma_{\alpha}$ & -0.0333 & -9.7930 & 0.00 & 0.0237 & 4.3350 & 0.00 & 0.1226 & 4.7826 & 0.00 \\
\hline$\sigma_{\beta}$ & 0.5190 & 18.2219 & 0.00 & 0.3362 & 9.2224 & 0.00 & 0.5374 & 12.4129 & 0.00 \\
\hline$\sigma_{\mathrm{w}}$ & 0.0974 & 69.2795 & 0.00 & 0.0786 & 37.3673 & 0.00 & 0.0324 & 0.3387 & 0.37 \\
\hline$a$ & -0.5936 & -9.7737 & 0.00 & -0.4945 & -2.7371 & 0.00 & -0.1952 & -2.6542 & 0.00 \\
\hline$b$ & -15.5193 & -4.3827 & 0.00 & -19.3663 & -1.7967 & 0.04 & -0.5934 & -0.1565 & 0.44 \\
\hline$c$ & -0.3383 & -3.7321 & 0.00 & -0.5652 & -6.2570 & 0.00 & -0.3250 & -2.1609 & 0.02 \\
\hline$d$ & -13.1563 & -1.9511 & 0.03 & -11.3331 & -1.5750 & 0.06 & -20.1251 & -1.3364 & 0.09 \\
\hline
\end{tabular}

\begin{tabular}{|c|c|c|c|c|c|c|c|c|c|}
\hline & \multicolumn{9}{|c|}{ Meteor shower from USA(t-1) to UK(t) with interest differential as variable $z$} \\
\hline $\bar{\alpha}$ & 0.0000 & 0.0178 & 0.49 & 0.0016 & 0.7633 & 0.22 & -0.0018 & -0.5558 & 0.29 \\
\hline $\bar{\beta}$ & 0.3612 & 12.6547 & 0.00 & 0.3999 & 9.8240 & 0.00 & 0.3580 & 9.3832 & 0.00 \\
\hline$\sigma_{\alpha}$ & 0.0799 & 24.8459 & 0.00 & 0.0485 & 12.6860 & 0.00 & 0.1203 & 8.5225 & 0.00 \\
\hline$\sigma_{\beta}$ & 0.5963 & 27.2603 & 0.00 & 0.6432 & 20.2416 & 0.00 & 0.4801 & 13.2814 & 0.00 \\
\hline$\sigma_{\mathrm{w}}$ & 0.0592 & 17.0737 & 0.00 & 0.0554 & 20.6492 & 0.00 & 0.0356 & 0.7960 & 0.21 \\
\hline$a$ & -0.4319 & -13.3402 & 0.00 & -0.6074 & -13.0424 & 0.00 & -0.2881 & -4.6445 & 0.00 \\
\hline$b$ & 7.4114 & 3.7561 & 0.00 & 9.7234 & 2.1979 & 0.01 & 6.7756 & 2.7556 & 0.00 \\
\hline$c$ & -0.0021 & -0.0295 & 0.49 & -0.0050 & -0.0501 & 0.48 & -0.0016 & -0.0113 & 0.50 \\
\hline$d$ & 0.0994 & 0.0195 & 0.49 & -5.2450 & -0.2800 & 0.39 & 2.4730 & 0.2997 & 0.38 \\
\hline
\end{tabular}

\begin{tabular}{|c|c|c|c|c|c|c|c|c|c|}
\hline & \multicolumn{9}{|c|}{ Meteor shower from UK(t-1) to Japan(t) with interest differential as variable $z$} \\
\hline $\bar{\alpha}$ & -0.0054 & -2.8429 & 0.00 & -0.0036 & -1.5292 & 0.06 & -0.0071 & -2.3275 & 0.01 \\
\hline $\bar{\beta}$ & 0.1346 & 6.3327 & 0.00 & 0.0792 & 2.8363 & 0.00 & 0.1826 & 6.3276 & 0.00 \\
\hline$\sigma_{\alpha}$ & 0.0606 & 1.7633 & 0.04 & 0.0178 & 1.4288 & 0.08 & 0.0464 & 4.4676 & 0.00 \\
\hline$\sigma_{\beta}$ & 0.3973 & 22.0043 & 0.00 & 0.2269 & 5.4747 & 0.00 & 0.4170 & 16.4545 & 0.00 \\
\hline$\sigma_{\mathrm{w}}$ & 0.0638 & 1.9901 & 0.02 & 0.0789 & 25.7861 & 0.00 & 0.0826 & 13.6044 & 0.00 \\
\hline$a$ & -0.1262 & -1.0233 & 0.15 & -0.4387 & -1.0806 & 0.14 & -0.3704 & -3.8698 & 0.00 \\
\hline$b$ & -0.0500 & -0.8969 & 0.18 & 0.2942 & 1.0808 & 0.14 & -0.1530 & -4.6839 & 0.00 \\
\hline$c$ & -0.0648 & -1.0711 & 0.14 & -0.0207 & -0.0520 & 0.48 & -0.1059 & -1.3118 & 0.09 \\
\hline$d$ & 0.0023 & 0.0396 & 0.48 & -0.1439 & -0.2857 & 0.39 & -0.0451 & -0.6959 & 0.24 \\
\hline
\end{tabular}




\section{References:}

Adjaoute, K., Bruand M. and R. Gibson-Asner. 1998. On the Predictability of the Stock Market Volatility: Does History Matter? European Financial Management 4: 293-319.

Baillie, R. and T. Bollerslev. 1990. Intra-day and Inter-market Volatility in Foreign Exchange Rates. Review of Economic Studies 58: 565-585.

Bekaert, G. and C.R. Harvey. 1997. Emerging Equity Market Volatility. Journal of Financial Economics 43: 29-77.

Bekaert, G. and C.R. Harvey. 2000. Foreign Speculators and Emerging Equity Markets. Journal of Finance 55: 565-613.

Bekaert, G., Harvey, C.R. and A. Ng. 2005. Market Integration and Contagion. Journal of Business 78: 39-69.

Bertero, E., and C. Mayer. 1990. Structure and Performance: Global Interdependence of Stock Markets around the Crash of October 1987. European Economic Review 34: 1155-1180.

Bollerslev, T., Chou, R.Y. and K.F. Kroner. 1992. ARCH Modelling in Finance: A Review of the Theory and Empirical Evidence. Journal of Econometrics 52: 5-59.

Campbell, J. Y., Grossman, S. J., and J. Wang. 1993. Trading Volume and Serial Correlation in Stock Returns. Quarterly Journal of Economics 108: 905-939.

Candelon, B., Hecq, A., and W.F.C. Verschoor. 2005. Measuring Common Cyclical Features During Financial Turmoil: Evidence of Interdependence Not Contagion. Journal of International Money and Finance 24: 1317-1334. 
Climent, F.J. and V. Meneu. 2003. Has 1997 Asian Crisis Increased Information Flows between International Markets? International Review of Economics and Finance 12: 111-143.

Connolly, R.A., and C.T. Stivers. 2003. Momentum and Reversals in Equity-Index Returns during Periods of Abnormal Turnover and Return Dispersion. Journal of Finance 58: 1521-1556.

Conrad, J.S., Hameed, A., and C. Niden. (1994). Volume and Autocovariances in Short-Horizon Individual Security Returns. Journal of Finance 49: 1305-1329.

Corsetti, G., Pericoli M., and M. Sbracia. 2005. Some Contagion, Some Interdependence: More Pitfalls in Tests of Financial Contagion. Journal of International Money and Finance 24: 1177-1199.

Engle, R., Ito, T., and W. Lin. 1990. Meteor Showers or Heat Waves? Heteroscedastic Intra-daily Volatility in the Foreign Exchange Market. Econometrica 58: 525-542.

Eun, C. and S. Shim. 1989. International Transmission of Stock Market Movements. Journal of Financial and Quantitative Analysis 24: 241-256.

Forbes, K.J. and R. Rigobon. 2002. No Contagion, Only Interdependence: Measuring Stock Market Comovements. Journal of Finance 57: 2223-2261.

Gagnon, L., and G.A. Karolyi. 2006. Price and Volatility Transmission across Borders. Financial Markets, Institutions and Instruments 15: 107-158.

Gagnon, L., and G.A. Karolyi. 2009. Information, Trading Volume and International Stock Return Comovements: Evidence from Cross-Listed Stocks. Journal of Financial and Quantitative Analysis 44: 953-986.

Gębka, B. 2012. The Dynamic Relation Between Returns, Trading Volume Volatility: Lessons from Spillovers Between Asia and the United States. Bulletin of Economic Research 64: 65-90. 
Granger, C., and M. J. Machina. 2002. Structurally-Induced Volatility Clustering. Working Paper No. 2002-15. University of California, San Diego.

Hamao, Y., Masulis, R., and V. Ng. 1990. Correlations in Price Changes and Volatility across International Stock Markets. Review of Financial Studies 3: 281-307.

Hamao, Y., Masulis, R., and V. Ng. 1991. The Effect of the 1987 Stock Crash on International Financial Integration. In: W. T. Ziemba, W. Bailey \& Y. R. Hamao (Eds.), Japanese Financial Market Research. Amsterdam: North Holland.

Harvey, C. 1991. The Term Structure and World Economic Growth. Journal of Fixed Income 1: 4-17.

Ibrahim B.M. and J. Brzeszczynski. 2009. Inter-regional and Region-specific Transmission of International Stock Market Returns: The Role of Foreign Information. Journal of International Money and Finance 28: 322-343.

Ibrahim B. M. and J. Brzeszczynski. 2012. The Relevance of the Strength and Direction of Return Signals from Foreign and Domestic Stock Markets to Investment Strategies. European Journal of Finance (forthcoming).

Ito, T., Engle, R.F. and W.-L. Lin. 1992. Where Does the Meteor Shower Come From? The Role of Stochastic Policy Coordination. Journal of International Economics 32: 221-240.

King, M.A. and S. Wadhwani. 1990. Transmission of Volatility between Stock Markets. Review of Financial Studies 3: 5-33.

Lee, S.B. and K.J. Kim. 1993. Does the October 1987 Crash Strengthen the Comovement among National Stock Markets? Review of Financial Economics 3: 89102.

Lin, W., Engle, R., and T. Ito. 1994. Do Bulls and Bears Move across Borders? International Transmission of Stock Returns and Volatility. Review of Financial Studies 7: 507-538. 
Llorente, G., Michaely, R., Saar, G., and J. Wang. 2002. Dynamic Volume-Return Relation of Individual Stocks. Review of Financial Studies 15: 1005-1047.

Longin, F. and B. Solnik. 2001. Extreme Correlation of International Equity Markets. Journal of Finance 56: 649-676.

Masih, A.M.M. and R. Masih. 2001. Long and short-term dynamic causal transmission amongst international stock markets. Journal of International Money and Finance 20: 563-587.

Melvin, M. and K. Hogan. 1994. Sources of Heat Waves and Meteor Showers in the Foreign Exchange Market. Journal of International Economics 37: 239-247.

Melvin, M. and B. Peiers Melvin. 2003. The Global Transmission of Volatility in the Foreign Exchange Market. Review of Economics and Statistics 85: 670-679.

Melvin, M. and M.P. Taylor. 2009. The Crisis in the Foreign Exchange Market. Journal of International Money And Finance 28: 1317-1330.

Nam, J.H., Yuhn, K.-H., and S.B. Kim B. 2008. What Happened to Pacific-Basin Emerging Markets after the 1997 Financial Crisis? Applied Financial Economics 18: 639-658.

Organisation for Economic Co-operation and Development (2012) - available at: http://www.oecd.org/eco/economicoutlookanalysisandforecasts/lookingto2060.htm (published and accessed on: $9^{\text {th }}$ November 2012).

Pagan, A.R. and G.W. Schwert. 1990. Alternative Models for Conditional Stock Volatility. Journal of Econometrics 45: 267-290.

Wang, S.S., and M. Firth. 2004. Do Bears and Bulls Swim across Oceans? Market Information Transmission between Greater China and the Rest of the World. Journal of International Financial Markets, Institutions and Money 14: 235-254. 
Wright, J. 2006. The Yield Curve and Predicting Recessions. Working paper No. 2006-7, Finance and Economics Discussion Series, Divisions of Research and Statistics and Monetary Affairs, Federal Reserve Board, Washington, D.C.

Yilmaz, K. 2010. Return and Volatility Spillovers among the East Asian Equity Markets. Journal of Asian Economics 21: 304-313. 